\title{
Crítica à leitura hayekiana da História: a perspectiva da ação política de Hannah Arendt
}

Angela Ganem

Professora visitante do Instituto de Economia da UFRJ

\section{Palauras-chave}

Friedrich August von Hayek, ordem espontânea, ação política, Hannah Arendt, mercado e democracia.

Classificação JEL B31.

Key words

Friedrich August von Hayek, spontaneous order, political action, Hannah Arendt, market and democracy.

JEL Classification B31.

\section{Resumo}

Mostrar as limitações da leitura hayekiana da História contrapondo-a à perspectiva teórica da ação política de Hannah Arendt é o objetivo deste texto. $\mathrm{O}$ artigo tem três partes constitutivas: na primeira parte, apresentamos a teoria hayekiana da ordem espontânea como uma ordem racional e leis tão inexoráveis quanto as que ele critica em Marx. Em uma palavra, a ideia do autodesenvolvimento do mercado visto como a única forma possível de organização para as sociedades contemporâneas. Na segunda parte, mostramos que conceitos caros ao liberalismo estão presentes em autores críticos, como Hannah Arendt, em que o indivíduo através da ação política constrói um mundo justo, conciliando liberdade individual com interesses coletivos. Finalmente, na terceira parte do artigo, contrapomos os dois autores, mostrando que o antídoto ao totalitarismo e o espaço da liberdade não estão no liberalismo ou na lógica do mercado, como advoga Hayek, mas na democracia, como pleiteia Arendt, conceito central do seu edifício teórico e espaço privilegiado da ação política, da liberdade e da justiça.

\section{Abstract}

The purpose of this paper is to demonstrate the limitations of a Hayekian reading of history, comparing it with the theoretical perspective of Hannah Arendt's political action.

The article constitutes of three parts: in the first part we present the Hayekian theory of spontaneous order as a rational order and laws as inexorable as the ones he criticizes in Marx; in other words, the idea of the market's self-development seen as the only possible way to organize contemporary societies. In the second part we show that concepts precious to liberalism are present in critical authors such as Hannah Arendt, for whom the individual in political action binds himself to the historical construction of a fair world, reconciling individual liberties with collective interests. Finally, in the third part of the article, we compare the two authors, showing that the antidote to totalitarianism, and the space for freedom is not to be found in liberalism or the market's logic, as Hayek advocates, but in democracy, as Arendt pleads, as the central concept of its theoretical building and privileged space for political action, freedom and justice. 
O texto tem como objetivo mostrar as limitações da leitura hayekiana da História contrapondo-a à perspectiva teórica da ação política de Hannah Arendt. O artigo tem três partes constitutivas: na primeira parte, apresentamos a teoria hayekiana $\mathrm{da}$ ordem espontânea, em que se sublinha, por um lado, a crítica que o autor faz a uma ordem fabricada pela razão e, por outro, os fundamentos da sua concepção de ordem espontânea do mercado. A partir daí, exploramos as contradições e as vicissitudes da teoria da ordem espontânea de Hayek, mostrando que, contraditoriamente ao seu discurso espontaneísta e, portanto, avesso ao desígnio racional, a teoria hayekiana serve, em última instância, ao autodesenvolvimento do mercado visto como a única forma possível de organização para as sociedades contemporâneas. Uma utopia tão racional quanto a crítica ao racional-construtivismo que ele identifica em Marx.

A segunda parte mostra que conceitos caros ao liberalismo, como individualismo, liberdade e regras de comportamento justas, estão presentes em autores críticos, como Hannah Arendt, que, ao considerar o agir autônomo, constitutivo da liberdade como a raiz do pensar e do julgar, compromete o indivíduo e o faz responsável na construção histórica de um mundo justo, conciliando liberdade individual com interesses coletivos. Finalmente, na terceira parte do artigo, procuramos contrapor as perspectivas dos dois autores mostrando que a ação política de Arendt coloca em seus devidos termos a crítica que Hayek faz ao totalitarismo. Para além do conformismo presente no totalitarismo, Arendt faz uma crítica contundente às sociedades de consumo naquilo que ela traz de mais pernicioso do ponto de vista político: a apatia, o desengajamento e a alienação. $\mathrm{O}$ texto conclui que o antídoto ao totalitarismo e o espaço da liberdade não estão no liberalismo ou na lógica do mercado, como advoga Hayek, mas na democracia, como pleiteia Arendt, conceito central do seu edifício teórico e espaço privilegiado da ação política, da liberdade e da justiça.

\section{Teoria e ideologia do mercado em Hayek}

F. A. Hayek (1899-1973) é considerado como uma das maiores expressões teórico-ideológicas do neoliberalismo. Sua teoria do mercado como uma ordem espontânea tornou-se uma das mais importantes referências teóricas da corrente neoliberal e, sem dúvida alguma, um veículo eficiente de difusão dos fundamentos da doutrina. 
Para Hayek, teoria e ideologia são elementos indissociáveis. Ele foi o principal articulador do colóquio que criou a Sociedade de Mont Pelérin, organização que presidiu por quatorze anos. Sua preocupação era reunir nomes da Europa e dos EUA para formar uma frente de reabilitação intelectual do liberalismo. O colóquio de Mont Pelérin de 1947 tinha como objetivo fundamental

"descobrir meios para enfrentar a crise moral, intelectual e econômica da Europa do pós-guerra, construindo um projeto político-econômico para um povo livre numa grande sociedade".

Como subproduto desse projeto, defendia a ideia de desmascarar os inimigos dessa sociedade aberta e de determinar as causas da crise europeia através de uma crítica contundente ao fascismo e ao stalinismo. Embora crítico ao totalitarismo nas duas grandes expressões em que esse se apresentou na História do século XX, Hayek concentrou-se no "caminho da servidão" instaurado pelo que considerou o racional construtivismo de Marx ou os dissabores do totalitarismo de uma ordem que é fruto do plano ou do desígnio de uma classe operária consciente. Hayek constrói sua crítica a Marx concentrando naquilo que seria o pecado capital da razão: uma razão onipotente ori- unda da classe operária que transformaria a sociedade numa máquina racional, uma razão que é capaz de digerir a própria complexidade e que constrói pela deliberação de seus sujeitos sociais um devir socialista (Hayek, 1973 e 1988).

Contra essa ordem fruto do plano em que bastaria a consciência e a ação revolucionárias para revelar o novo mundo, Hayek parte de regras espontâneas e advoga uma Teoria da Evolução Cultural, que se define por um processo de experimentação dos homens na História e que resulta sempre na escolha de regras que reafirmam incondicionalmente a concorrência ou a ordem catalítica do mercado, a única ordem que garante a liberdade e que se constitui na melhor forma de organização das sociedades contemporâneas. A palavra "utopia", associada histórica e genealogicamente ao socialismo como instauração de algo novo, foi abraçada por Hayek. Ele afirmava que

\section{"a principal lição que um verdadeiro libe- ral deve reter do sucesso dos socialistas foi a sua coragem de serem utópicos. Só assim que poderemos fazer dos fundamentos filo- sóficos de uma sociedade livre algo vivo" (Hayek, 1967).}

Para enfrentar o principal inimigo de uma sociedade livre, o totalitarismo, nas suas duas versões do século 20, o stalinis- 
mo e o fascismo, Hayek toma como ponto de partida uma crítica filosófica ao racionalismo construtivista, ou a ideia de uma ordem fabricada, oriunda do desígnio da razão. Sua crítica filosófica se dirige ao racionalismo de tradição cartesiana, em que o espírito humano, através do bom uso de um método rigoroso e universal (ta mathema), atinge verdades absolutas e inquestionáveis, sem o recurso de referências empíricas. Como derivação desse método racional, a ação orientada por essa razão onipotente tem a capacidade de construir ordens sociais, ${ }^{1}$ independentemente da História ou da tradição. Da pretensão que ele identificou de que a razão pode criar uma ordem social, Hayek articulou uma segunda crítica: a servidão e o totalitarismo instaurados por essas ordens supostamente fabricadas. Segundo o ponto de vista de Hayek, o racionalismo construtivista do processo de criação da ordem social socialista produziu de suas entranhas uma razão totalitária. A identificação do totalitarismo ao socialismo e o abandono da ênfase na questão fascista mostraram que Hayek estava interessado não no debate entre totalitarismo versus democracia, mas no confronto entre ordem socialista e ordem social do mercado, ou seja, no confronto em torno de projetos de sociedade. Nesse contexto, afirmou que, contra o totalitarismo ou uma ordem raci- onal fruto do plano, só um antídoto possível: a ordem liberal do mercado.

A ordem liberal do mercado, para Hayek, está associada à ideia de ordem espontânea que tem sua origem, sobretudo, na ordem natural de Adam Smith. Ela é catalítica (katallatein), que significa trocar e se preservar no mito da mão invisível. Sobre a origem dessa noção na história das ideias e a sua contraposição à ideia de uma ordem racional, fabricada, ele afirma:

Foi numa reação contra o racionalismo cartesiano que os moralistas britânicos do séc. XVIII [...] elaboraram uma teoria social que faz dos resultados não previstos das ações individuais seu objeto central, propondo uma teoria geral da ordem espontânea do mercado [...].

A origem da idéia está na filosofia moral britânica do séc. XVIII de Mandeville. Mas o seu desenvolvimento completo só acontece com Montesquieu (que sofre influência de Mandeville), e em particular de David Hume, Josiah Tucker, Adam Ferguson e Adam Smith, este último afirma que uma mão invisivel conduz o bomem a servir a um fim que não faz parte de suas intenções [...], aliás, a percepção mais profunda do objeto de toda teoria social (Hayek, 2007, p. 162-164).

A ordem espontânea de Hayek, como a de Smith, é o resultado de ações não

\footnotetext{
1 Hayek identifica

onipotência da razão no racionalismo cartesiano e nas consequências diretas que ele extrai desse método: a ação racional é aquela inteiramente conhecida e demonstrável pela razão, e as realizações dos homens são produtos de seu raciocínio. Em suas palavras: "A raz̃ão do homem por si só torná-lo-ia capaz de construir a sociedade em novos moldes" (Hayek, 1973, p. 4).
} 
intencionais. Uma espontaneidade que está muito distante da concepção neoclássica de uma ordem do mercado ditada pela razão. Para Hayek, o modelo neoclássico é uma variante do racional construtivismo e ele a identifica em três planos: no indivíduo autointeressado, detentor de uma razão calculadora, cujas escolhas, produto de uma previsão racional ou de um desígnio intencional, acarretariam como resultado econômico uma ordem do mercado racional equilibrada, estável e ótima. No teóricomodelizador que aspira demonstrar matematicamente a superioridade do mercado e, finalmente, no político ou no governo que aspiram que o Estado corrija os efeitos nefastos do mercado. A mesma concepção de onipotência da razão que dita a racionalidade ilimitada do indivíduo e a arrogância do modelizador dão alimento a uma fragilidade imperdoável dos neoclássicos: a ideia de que é possível não apenas demonstrar o mercado, como corrigi-lo, reformá-lo, alterando a distribuição natural da renda (Ganem, 1996). Uma interferência que significa para Hayek negar ao mercado o seu desenvolvimento espontâneo e dar passos, com essas intervenções, em direção ao socialismo.

O indivíduo é o ponto de partida da teoria hayekiana; as regras, o elemento estruturante; e a ordem espontânea, a sua resultante. $\mathrm{O}$ indivíduo, fundamento da or- dem, é um homem livre, ignorante e seguidor de regras. A liberdade entendida como a essência da aventura humana é a liberdade negativa, concepção do direito liberal ou a garantia pela lei da ausência de coerção exercida por outrem. A ignorância, atributo até então desqualificado das teorias ortodoxas, fornece novos elementos à racionalidade e abre para novos domínios teóricos como o da sociologia, em que as regras têm papel estruturador na inteligibilidade das ordens sociais. $\mathrm{O}$ indivíduo hayekiano tem conhecimento limitado, incompleto e fragmentado ante um mundo complexo, que ele sabe que jamais será totalmente desvelado. A ordem espontânea é, portanto, para ele uma categoria opaca, inacessível à razão. Como ela não é construída por ninguém, não pode ser reconstruída mentalmente, caracterizando-se por ser uma estrutura transcendental que expressa uma multiplicidade de fins distintos e incomensuráveis de todos os seus membros individuais (Hayek, 1974). O elevado número de variáveis presentes nos fenômenos sociais impossibilita o conhecimento de todas as circunstâncias que envolvem a ação dos indivíduos, o que confere uma natureza complexa aos fenômenos sociais, não sujeita a simplificações e reducionismos.

Os homens, agindo livremente num processo aberto de experimentações, tateiam, 
entre erros e acertos, como num processo popperiano do conhecimento movido por conjeturas e refutações. No objetivo de adaptar-se às circunstâncias, fazem uso do conhecimento que dispõem, ainda que limitado. Através de um conhecimento tácito, o homem experimenta, aprende e seleciona as melhores regras de comportamento justas, abstratas e gerais que o guiam nesse mundo complexo. Essas regras hayekianas emergem nesse quadro de ignorância e sabedoria, incerteza e seleção. O indivíduo, no seu atuar cego, desconhece o resultado coletivo, mas esse conhecimento tácito confere ao individualismo de Hayek uma natureza complexa, uma boucle auto-referencielle, na expressão de Dupuy, ou a ideia de uma ligação do sujeito a ele mesmo, via o social (Dupuy, 1992).

Avesso ao racionalismo construtivista de origem cartesiana, Hayek se identifica com o racionalismo crítico popperiano com suas proposições constantemente renovadas, sua humilde correção de erros e sua consequente provisoriedade do conhecimento. Sua teoria joga novas luzes ao conceito de racionalidade, problematiza a questão do conhecimento, além de trazer as regras para o centro teórico, fornecendo um elemento importante para a inteligibilidade da ordem social. Com isso, estabelece um fino diálogo com a heterodoxia, renovando e tornando accessível o discurso teórico do mercado no século XX.

Essa ordem espontânea auto-organizada é regida por regras abstratas. Garantidos os fundamentos da ordem, a concorrência engendrará a riqueza, o bem-estar social e a justiça das greats societies. O papel do governo nesse quadro é fazer respeitar o fundamento lógico de uma sociedade livre, isto é, entender que a diferença de oportunidades está relacionada com as eficácias individuais do processo de descoberta constituído pelo mercado. $\mathrm{O}$ intento de tornar as oportunidades de indivíduos iguais produz injustiças. Para evitar os efeitos nefastos do racionalismo construtivista, Hayek sugere que o Estado garanta os direitos negativos do cidadão: somente as regras de um governo que favorece o funcionamento catalítico do mercado aumentariam as chances de todos.

Nesse ponto, veremos que Hayek extrapola os limites do econômico ou de qualquer disciplina stricto sensu para se colocar no plano da filosofia social e da teoria da História. Hayek, na sua Teoria da Evolução Cultural, afirma que, quanto mais a sociedade se torna complexa, mais acertadas e espontâneas são as regras. Em verdade, os homens terminam por eleger as regras que garantem os meios para servir 
uma variedade de propósitos, ou que sejam aplicáveis a um número desconhecido e indeterminado de casos, ou seja, as regras da concorrência. Esse processo impessoal e inexorável reafirmaria na História o jogo catalítico do mercado, o único capaz de produzir riquezas.

Embora Hayek advogue que o importante é explicar como funciona o processo sem tentar explicar seus resultados ou predizer o seu curso, numa clara crítica à utopia marxista, o que se constata ao fim e ao cabo de sua Teoria da Evolução Cultural é a reafirmação de um processo de autodesenvolvimento do mercado na História. Ainda que não saibamos de antemão quais são as regras eleitas, as regras da concorrência são sempre as exitosas. São elas que, no seu entender, reproduzem os fundamentos do mercado, a forma mais eficiente de funcionamento das sociedades. E, nesse caso, todas as iniciativas participam da autorrealização do mercado (Ferry, 1994; Ganem, 2006). A essa altura, algumas questões ficam pendentes na sua teoria. Atenhome a duas que considero pertinentes para o objetivo proposto. São elas:

1. como justificar que as regras da concorrência serão sempre as melhores, as exitosas, enfim, sem sair do campo da espontaneidade e da não previsibilidade do curso da História, seu território preferido, para entrar no campo de uma necessidade racional?

2. como criticar o racionalismo de Marx, em que ele supostamente buscaria como um mito racional descobrir leis imutáveis e eternas para a História se ele próprio reedita o mito da mão invisível e entende o mercado como passado, presente e devir para as sociedades contemporâneas?

E foi exatamente esse aspecto da inexorabilidade do mercado com a simultânea euforia do triunfo da democracia liberal como a forma final dos governos que alimentou o debate sobre o fim da História na década de noventa do século passado. Essa discussão que entrou em quase todos os campos do saber teve como eixo central filosófico a ideia da inexorabilidade do mercado, processo sem sujeito perfeitamente ilustrado em Hayek. A inexorabilidade do mercado significa, em outras palavras, o fim da utopia socialista e a sua substituição pela ordem liberal. É como se a humanidade atingisse o ponto final de sua evolução ideológica ou atingisse a forma final dos governos humanos com o triunfo da democracia liberal. Hayek, ao fazer uma defesa incondicional do mercado como a me- 
lhor forma de organização das sociedades contemporâneas, deixa claro que a ideologia e a teoria do mercado se realimentam mutuamente. Inúmeras consequências ideológicas, comportamentais, éticas e políticas podemos extrair dessa conjunção. $\mathrm{O}$ aniquilamento da política foi certamente uma das mais graves consequências e uma das preocupações centrais do pensamento de Hannah Arendt, assunto que exploraremos a seguir.

\section{2_A perspectiva da ação política de Arendt}

Elegemos a reflexão filosófica da política e da ação dos homens na história de Hannah Arendt não apenas porque podemos apresentar, ainda que, em linhas gerais, sua densa e provocante contribuição, como também porque, com base em seu pensamento, é possível reforçar as contradições e as incongruências das críticas que Hayek fez a Marx, situando sob novas bases a crítica ao racional construtivismo e ao totalitarismo. A contribuição de Arendt não apenas lhe confere autoridade para criticar os rumos totalitários que o comunismo tomou, como serve para desconstruir a leitura hayekiana da História e do agir humano no próprio terreno em que Hayek se move. A obra de Arendt renova o pensar sobre os homens, sua ação e a História e produz uma reflexão filosófica de tal envergadura sobre a História que termina sem esforço colocando, nos seus devidos termos, ou seja, ideológicos e retóricos, a visão evolucionista da história de Hayek.

Para tratar desse assunto, desenvolveremos, a seguir, três aspectos da obra de Hannah Arendt que nos permitirão estabelecer contrapontos à perspectiva teórica de Hayek, questão a ser tratada com ênfase na última parte do trabalho. Um primeiro aspecto, ponto de partida de ambas as reflexões, trata da crítica ao totalitarismo e ao racional construtivismo. Um segundo ponto analisa a importância crucial do indivíduo e da liberdade em Arendt e, finalmente, um terceiro aspecto sublinha a ação do homem na História e serve para mostrar a utopia da democracia para Hannah Arendt.

A primeira ordem de questão diz respeito à crítica ao totalitarismo, elemento que chamou a atenção tanto de Arendt como de Hayek, autores contemporâneos, marcados pelo engajamento intelectual e político do seu tempo. Como sabemos, Hannah Arendt (1906-1975) é uma filósofa sensível às agruras do século XX e não passa ao largo do desastre político produzido pelo totalitarismo, seja ele fascista, seja ele stalinista, retirando dele lições e conse- 
quências que marcam profundamente a sua teoria. Arendt na sua obra faz uma crítica visceral a todas as formas de totalitarismo. No que diz respeito ao nazismo, formula a seguinte questão: que leis da psicologia de massa explicam por que milhões de seres humanos se deixam levar sem resistência às câmaras de gás? E ela mesma responde a partir de um eixo teórico inegociável, ponto de partida metodológico para sua reflexão: o totalitarismo tem como meta determinada destruir o indivíduo e a sua espontaneidade. Destruir, portanto, a individualidade, ou assassiná-la, para ser fiel aos próprios termos, significa atingir o seu âmago: destruir a espontaneidade ou o poder do homem de começar qualquer coisa de novo a partir dos próprios recursos. Os que aspiram à dominação total devem, portanto, liquidar implacavelmente a espontaneidade. A individualidade é intolerável, e o poder total só pode ser preservado num mundo de reflexos condicionados de cachorros pavlovianos, de marionetes que não apresentam a menor suspeita de espontaneidade (Arendt, 1972, p. 265).

No que se refere ao totalitarismo do comunismo stalinista, Arendt não titubeia e afirma que a tomada de poder de Stalin e a transformação da ditadura do partido único em dominação total transformam as classes em massa, eliminando paralelamen- te toda a solidariedade de grupo, condição sine qua non para a dominação total.

'As massas, nos diz Hannah, em As origens do Totalitarismo, [...] não estão ligadas pela consciência do interesse comum, elas não têm lógica específica de classes que se exprime pela perseguição de objetivos precisos, limitados e acessiveis'. [...] O termo massa se aplica tão somente a pessoas que, seja pelo seu número, seja pela indiferença, seja por estas duas razões, não podem se integrar em nenhuma organização fundada sobre o interesse comum (Arendt, 1972, p. 49).

A aguda crítica ao totalitarismo e a defesa da individualidade e da espontaneidade da ação humana através da recuperação do indivíduo conquanto capacidade para agir, pensar e julgar com discernimento são para a autora os verdadeiros antídotos e a única possibilidade concreta que os homens dispõem para barrar projetos totalitários. Se o totalitarismo significa para os homens que vivem sob o seu jugo um pensar que não compreende, um agir que se dá mecanicamente e uma incapacidade de julgar, será exatamente na preservação da natureza intrínseca desses elementos aparentemente perdidos que será possível escapar das dicotomias: indivíduo/liberdade, de um lado, e sistema/totalitarismo, de outro. 
Em verdade, para a autora, o homem, diante dos riscos incautos que a ação lhe confere, assusta-se com a possibilidade de viver em liberdade e termina por condenar a ação na sua espontaneidade, circunscrevendo-a à necessidade, a tábua de salvação para a perturbação que a falta de controle sobre o destino lhe traz. Assim consiste a crítica que Arendt procede à concepção marxista, ou a noção marxista de fabricação da História. Nos próprios termos:

"Nem a liberdade, nem nenbum outro sentido podem ser produtos de uma atividade humana como a mesa é produto da atividade do marceneiro" (Arendt, 1972, p. 105).

E é através desse argumento que reside a sua crítica à luta de classes de Marx como a fórmula mágica que desvendaria todos os segredos da História, na fabricação de uma coisa que, tendo um começo e um fim, persegue leis de movimento determinadas ao mesmo tempo em que dissolve e aniquila nesse processo as particularidades e os sofrimentos individuais. Para Arendt, num quadro de revolução, supera-se aparentemente o conformismo (pelo fato de ter sido realizada a revolução), mas a sociedade comunista pode recair num novo tipo de conformismo em que a liberdade individual é absorvida pela comunidade. O animal laborans na sociedade socialista não necessariamente se ocupa dos interesses públicos; seu conformismo pode significar se encapsular nos seus interesses privados. O campo da necessidade não necessariamente leva a uma constante politização e à liberdade. Arendt problematiza em torno dos descaminhos do movimento operário europeu e russo, que abriram mão de sua radicalidade assim que se viram satisfeitos em suas reivindicações econômicas básicas. Arendt afirma que o movimento operário no seu momento inaugural

"foi o único grupo no cenário político que, além de defender seus interesses econômicos, travou uma luta inteiramente politica [...]. Entretanto este papel revolucionário do movimento operário está chegando ao fim" (Arendt, 1972).

Marx, para a autora, comete o equívoco de prever que somente a Revolução poderia provocar a decadência do Estado e abrir caminho para o reino da liberdade. Para Arendt, o Estado deve ser preservado conquanto espaço político resistindo à uniformização do social ditado pelos interesses privados. O reino da liberdade contrário à uniformização estaria expresso no confronto de opiniões presentes numa verdadeira democracia construída por uma participação política ativa e constante. E o que seria essa verdadeira democracia? Certamente nada semelhante às democracias representativas fundadas em partidos políticos das 
sociedades de massa em que os partidos funcionam como especialistas da coisa pública, guardiões de uma liberdade associada ao momento do voto. Arendt, em as Crises da República, defende a construção de Conselhos, que seriam ilhas da liberdade, verdadeiras bases fundadoras de uma nova forma de governo: a verdadeira Respublica (Arendt, 1973).

É interessante que o eixo Arendtiano da crítica ao totalitarismo, caracterizado pela perda da espontaneidade e da ação política, gerando conformismo, termine por levá-la a uma aguda análise da alienação dentro das sociedades capitalistas. Preocupada e implicada com a democracia, ela atinge com sua crítica o mercado através do consumismo (que pode acarretar o despotismo de uma sociedade de massa) e que é o elemento vital de sua forma de reprodução. Ao defender o modelo político da polis grega, em que a ação política é a peçachave da liberdade individual, e sendo restrita aos cidadãos, ela se preserva de qualquer manipulação. Arendt lamenta que, na sociedade de massa, no esforço de promover uma uniformização do comportamento consumista, ocorre um movimento em direção ao conformismo, negando a pluralidade da discussão. De fato, nessa sociedade o homem garante a sua sobrevivência no despotismo de uma única opinião, posto que essa sociedade é guiada pelo "labor", entendido como produtos de objetos feitos para ser descartados, o que significa um consumismo desenfreado, em última análise.

Em $A$ crise da cultura, Arendt nos alerta para:

[...] os traços da psicologia coletiva do homem de massa: seu abandono - abandono que não é nem isolamento, nem solidãoindependente de sua faculdade de adaptação; sua excitação e sua falta de critérios; sua atitude voltada para o consumismo acompanhada de uma incapacidade de julgar ou mesmo de distinguir, e por trás de tudo isto, seu egocentrismo e uma alienação do mundo... (Arendt, 1972, p. 255).

Essa crise da cultura própria da sociedade de massa, que maltrata a individualidade no sentido de produzir abandono, isolamento, solidão e consumismo, produz o que ela considera o mais grave para a humanidade: a alienação expressa na sua incapacidade de julgar e de discernir, ficando o homem suscetível à manipulação.

Sua crítica ao consumismo atinge o coração do mercado capitalista como forma de organização da sociedade e é particularmente atual. São inúmeros os autores contemporâneos que recorrem a Arendt, como referência teórica crítica, identificados com a sua análise acerca da sociedade que hoje vivemos: injusta, desprovida de 
valores éticos humanistas e marcada pela moral do entretenimento e pelo consumismo. ${ }^{2}$ A sociedade de massa dessa great society leva, segundo a autora, a anulação da cultura, dando lugar à banalização do entretenimento e ao conformismo, o que, para Hannah Arendt, é o elemento central que pode levar à destruição da humanidade. As consequências constatadas pela autora são as mais desastrosas: apatia política, conformismo e alienação.

A segunda ordem de questão diz respeito ao ponto de partida metodológico de sua análise: o indivíduo, por meio daquilo que marca a sua potencialidade, a ação livre, espontânea e contingente. Todos os elementos se irmanam para recuperar não apenas o homem para a vida ativa, mas, sobretudo para a política, já que ela é o elemento constitutivo da liberdade e da capacidade de iniciar algo novo, não previsto pelos mecanismos causais do mundo. Além disso, Arendt não descuida da análise histórica e da sua perturbadora contingência. Mesmo seguindo alguns princípios de Kant, Arendt sublinha as diferenças que percebe entre ela e Kant, no que tange à distância que existe entre a ciência (regida por conceitos, leis e sistemas) e o pensamento (que busca a significação, a compreensão). Enquanto o compromisso da ciência é com a busca da verdade, o pensamento é como

um diálogo socrático que busca a compreensão. $\mathrm{O}$ homem, através do pensar, é capaz de transcender, não se sujeita a critérios apriorísticos próprios dos cânones científicos, e sua ação pautada pelo pensamento assume os riscos e o medo perante o desconhecimento dos rumos que o livre agir provoca.

O indivíduo para Arendt age de três formas, e é desse entendimento inicial que consiste uma das chaves para a compreensão de sua obra. A primeira forma de ação tem sua expressão máxima ligada à liberdade e ao agir na política e se define por uma ação que não tem fim e cujo objetivo final o homem desconhece. A segunda forma de ação é a caracterizada pelo homo faber, que significa a fabricação de uma coisa que tem começo e um fim e, portanto, leis de movimento determinadas. ${ }^{3}$ Já a terceira for-

2 Consultar Jurandir Freire Costa, que toma por base Arendt para tecer uma crítica ao consumismo e à moral do espetáculo em $O$ vestígio e a aura (Garamond, 2004), além de $A$ arte de reduzir as cabeças; sobre a nova servidão na sociedade ultraliberal (Dufour, 2005) e O império do efêmero (Lipovestsky, 2004).

3 Esta noção está intimamente ligada à noção marxista de fabricação de História, o que faz a autora afirmar que "nem $a$ liberdade, nem nenbum outro sentido podem ser produto de uma atividade bumana como a mesa é o produto da atividade do marceneiro" (Arendt, 1987, p. 105). E, numa passagem da Condição Humana, ela afirma: "Enquanto a força do processo de fabricação é inteiramente absorvido e exaurido pelo produto final, a força do processo da ação nunca se esvai num único ato, mas ao contrário pode aumentar a medida que se multiplicam as consequiencias" (Arendt, 1981, p. 245). 
ma é ditada pelo animal laborans, que significa o trabalho voltado para a produção de consumo, o que hoje simboliza a produção para o desperdício. Arendt critica a herança marxista de que o homem só conhece o que faz e afirma que Marx, ao cancelar a distinção entre o operar e o agir, obscureceu o papel da política, um dos três componentes fundamentais da vida activa. ${ }^{4} \mathrm{O}$ animal laborans, ao adquirir o estatuto de assalariado, procura a subsistência da sua vida e de sua família pelo consumo, longe de qualquer produção técnica e da ação política. A promoção social pelo labor faz do espaço público um processo de afirmação à sobre-

\footnotetext{
4 Para Arendt, poesis é operar, fazer, tecné, enquanto que praxis é agir, substância da política e parte integrante juntamente com o trabalho de vida ativa. $\mathrm{O}$ ato ou o agir em processo possui as seguintes características: 1) a ignorância - quando se age nunca se sabe exatamente o que se está fazendo;

2) a responsabilidade $-O$ homem é sempre responsável pelas conseqüências de se seu ato, ainda que não o tenha previsto ou desejado;

3) a não reversibilidade - $O$ homem não pode desfazê-lo; 4) a infinitude - o processo desencadeado pelo ato jamais termina;
}

vivência biológica, circunscrevendo a excelência à esfera do labor, conquanto que, para a autora, a excelência só pode existir na ação política e no confronto de opiniões.

A ação, diz Arendt, referindo-se a sua primeira forma, é a única atividade que se exerce diretamente entre os homens sem a mediação das coisas ou da matéria. Na verdade, ela corresponde à condição humana de pluralidade e, como expressão inequívoca da individualidade, carrega consigo a fonte do significado da vida humana. Embora as ações fugazes e perecíveis da vida política nunca cumpram a sua intuição original e desencadeiem alguma coisa que não pode ser prevista, Arendt, em $A$ condição bumana, afirma com contundência que:

$$
\begin{aligned}
& \text { "[...] a única forma capaz de realizar fei- } \\
& \text { tos não é nem a capacidade teórica, nem a } \\
& \text { razão, mas a faculdade humana de agir, } \\
& \text { de iniciar processos novos e sem preceden- } \\
& \text { tes, cujo resultado é incerto e imprevisivel, } \\
& \text { quer sejam desencadeados na esfera huma- } \\
& \text { na ou no reino da natureza”" (Arendt, 1987, } \\
& \text { p. 243). }
\end{aligned}
$$

O sentido da política é a própria realização da liberdade como nascimento de algo novo, inesperado e imprevisível. ${ }^{5}$

Ao criticar a sociedade de massa como sistema que destrói a coexistência da esfera privada com a esfera pública, Arendt chama a nossa atenção para a falta de con- 
dições do desenvolvimento daquilo que é essencial na vida humana, que é a pluralidade de opiniões num espaço público comum. Ao afirmar o reino da liberdade no espaço público e democrático, Arendt está nos falando de um indivíduo que é livre, humanista, cuidadoso e, sobretudo, corajoso e implicado com os destinos da polis.

A terceira ordem de questão diz respeito ao agir dos homens na História. Arendt entende que a História construída com base na ação humana é uma abertura para infinitas possibilidades. Em verdade, vivemos num processo que

"não se conbece nem começo nem fim e que, em conseqüência disso, não nos permite nutrir esperanças escatológicas” (Arendt, 1972, p. 92).

Essas afirmações de Hannah Arendt não deixam de ser perturbadoras e instigantes e, talvez por isso, acarretem "certo constrangimento intelectual que deriva da própria natureza de sua obra". ${ }^{6} \mathrm{Em}$ bora Arendt questione os objetivos grandiosos da política no que tange a como estabelecer uma nova sociedade, ou como fazer uma guerra para acabar com todas as guerras, ou ainda como assegurar a democracia no mundo inteiro. Arendt, ao fazer o elogio da política, "salva a espontaneidade revolucionária, mas não a violência fa- bricada do projeto revolucionário" (Abranches apud Arendt, 2002, p. 9).

Entretanto, a questão central é que Arendt não perde a esperança no homem e na sua capacidade de julgar e discernir entre o bem e o mal e, portanto, de fazer escolhas desinteressadas e liberadas de seus interesses privados imediatos. Para a autora, é necessário não perder a esperança da construção de um mundo não totalitário e procurar na própria condição humana a capacidade de abrir, de preservar ou de reconstruir um espaço público. ${ }^{7}$ A liberdade, nesse sentido, só pode ser exercida mediante a recuperação e a reafirmação do es-
Correa intitulado Transpondo o abismo: Hannah Arendt entre a Filosofia e a Politica, Forense Universitária, 2002, em que são explorados vários aspectos filosóficos e políticos da obra da autora.

7 É dentro dessa perspectiva que Paul Ricoeur entende a obra $A$ condição bumana, de Arendt: livro de filosofia antropológica, que tem como objetivo construir a resistência e a reconstrução do espaço público, após o desastre do totalitarismo. Ricoeur, P., moderne, Calmann-Levy, 1981. 
8 Segundo Celso Lafer, o interesse maior de Arendt é a respublica e é por isso que, para ela, liberdade não é a liberdade moderna e privada da não interferência, mas sim liberdade pública de participação democrática. Daí para a autora a importância do nós no agir conjunto. Ação, palavra e liberdade não são coisas dadas, mas requerem a construção e a manutenção do espaço público. Celso Lafer, prefácio de Arendt, H. A condição bumana, Forense Universitária, 1981. paço público, pois só no mundo político é que será possível desenvolver a identidade individual na comunidade política. ${ }^{8}$ E é por isso que Hannah Arendt, ao considerar a ação política como elemento constitutivo da liberdade e como a raiz do pensar e do julgar, implica o indivíduo com a polis e o faz responsável na construção histórica de um mundo justo, capaz de conciliar liberdade individual com interesses coletivos.

\section{O mercado de Hayek versus a democracia de H. Arendt}

As três ordens de questões tratadas na análise que fizemos de Arendt servem de contraponto à teoria de Hayek. A crítica ao totalitarismo, a importância crucial do indivíduo e sua ação na História reforçam e elucidam as utopias que estão em jogo por detrás desses dois autores: o mercado para Hayek, e a democracia para Arendt.

A crítica que Hayek faz ao totalitarismo é tendenciosa porque concentra naquele que ele considera ser o seu maior inimigo estratégico - Marx, através do pecado capital da teoria marxista - a defesa de uma razão onipotente que permitiria à classe operária transformar a sociedade numa máquina racional, capaz de construir um devir socialista. Embora acuse a ambos, o stali- nismo e o fascismo, de totalitários e produtos diretos de ordens que seriam fruto do plano e do desígnio, ele destaca na sua crítica a servidão imposta pelo totalitarismo stalinista. Já adiantamos essa limitação do autor na primeira parte deste trabalho. É interessante, entretanto, mais uma vez sublinhar que o mesmo eixo filosófico racional-construtivista que ele se utiliza para a crítica ao marxismo permite que se percebam as contradições de seu projeto hiper-racionalista do mercado. Irônica e contraditoriamente, ele substitui a escatologia marxista pela utopia do mercado. Esse crítico do totalitarismo é no fundo um prisioneiro da ideia de uma defesa incondicional do mercado como a melhor forma de organização para a sociedade.

A crítica de Hannah Arendt a todas as formas manifestas de totalitarismo, em vez de aprisioná-la, atinge diretamente a ordem social do mercado, colocando nos seus devidos termos, isto é, ideológicos, a crítica de Hayek a Marx. Por que se concentrar no totalitarismo do racional construtivismo das economias comunistas, perguntaria ela, se a massificação, o conformismo, a alienação própria das sociedades capitalistas de consumo são elementos devastadores e destruidores da cultura, transformando o homem num ser rude, bruto, isolado, quase um ser hobbesiano do estado de natureza? 
Essa lógica confina o homem nos seus terrenos privados e alimenta a ideia de que nada se pode fazer quando se trata do mercado: afinal ele é inexorável e, portanto, a própria expressão do fim da História. Esse fatalismo ideológico fragiliza o indivíduo, anula as potencialidades de seu agir conjunto na política e o faz descrente de sua capacidade de irromper algo novo que the permita descortinar outras possibilidades no plano da História.

O indivíduo, como vimos, é o ponto de partida e peça angular na construção dos edifícios teóricos desses dois grandes autores do século XX. O animal seguidor de regras de Hayek é o indivíduo que, no exercício de sua liberdade, escolhe regras através de um processo de experimentação humana de acertos e erros, o que garantiria, num primeiro momento, uma abertura infinita de possibilidades. Entretanto, esse indivíduo autointeressado do discurso ultraliberal hayekiano, que, por uma mágica da mão invisível, produz bem-estar social, é uma peça da sua Teoria da Evolução Cultural, em que a História se apresenta como um processo inexorável de autodesenvolvimento do mercado.

$\mathrm{Na}$ verdade, ao selecionar as regras da concorrência como as necessárias que garantem a liberdade e a justiça, ele reitera uma concepção da História que segue o curso natural do mercado como passado, presente e devir. Nesse sentido, ele passa sutilmente do campo do espontâneo para o campo do necessário. $\mathrm{O}$ indivíduo hayekiano defende regras de comportamento justas e fiáveis porque os homens sempre selecionam as regras da concorrência, que, no limite, são as regras necessárias de Hayek que garantem a ordem catalítica do mercado. Essas regras são válidas, desde que não firam a ideia de um Estado que garanta a concorrência e se limite às suas funções mínimas, já que qualquer plano ou planificação nos negócios públicos é perturbador da livre iniciativa individual e do exercício das liberdades plenas.

Embora Arendt não tenha criticado diretamente Hayek, ao sublinhar a importância dos juízos e do discernimento como elementos cruciais da ação livre, ela é crítica com relação às regras da tradição ou às regras eleitas do comportamento justo, tão caras ao autor. Poderíamos depreender facilmente de sua análise sobre a crise da cultura a seguinte questão: se o homem é manipulado, se ele não compreende e se está mergulhado numa crise moral característica dessa sociedade atual, como podemos garantir que elegerá regras fiáveis? Para ela, o homem, antes de ser um animal que segue regras, é um homem de ação, e essa depende de uma boa compreensão e de um 
bom julgamento. Além disso, é a ação política, sobretudo, a fonte da individualidade e de significação da vida humana. Nela reside o significado profundo da liberdade do indivíduo, rompendo muitas vezes com a tradição e as regras instituídas, dando início a algo novo.

A imposição da lógica do mercado como necessária e inexorável, além de tentar inibir a irrupção de algo novo, tem um traço economicista, no sentido em que tenta submeter todos os aspectos da vida à lógica da eficiência e das tecnicalidades. A noção de progresso, ao invés de se inspirar em ideias transcendentes, restringe-se a ser o resultado mecânico da livre concorrência. A política no sentido arendtiano torna-se inútil neste mundo de mônadas, conformadas e dominadas pela lógica do mercado: consumidores vorazes, encantonados em sua vida privada e distantes dos interesses públicos.

A submissão da política à sociedade do consumo e do espetáculo tem como sua mais pura expressão a apatia e o conformismo dos cidadãos perante um curso da História que só aponta um caminho: o autodesenvolvimento do mercado. O ideário liberal, embora valorize o indivíduo e a liberdade, ironicamente termina por conceber um indivíduo que encena o que já está predeterminado. Para Arendt, não há como pensar em liberdade quando o prazer da política no espaço comum da vida pública é substituído pelo consumo e pela lógica do mercado. Arendt faz a denúncia do esquecimento da política e afirma que o homem pensa, julga e é capaz de ação, ação esta que se constitui no centro nevrálgico de todas as possibilidades humanas, caminho aberto para o exercício do confronto de opiniões.

Menos do que adequação, conformismo e adaptação do homem à lógica do mercado, Hannah supõe a urgência do pensamento sobre o agir e afirma que o reino da liberdade só pode ser alcançado no espaço público e democrático. A democracia é para Arendt o verdadeiro antídoto contra o totalitarismo e é a utopia que deve substituir a falta de esperança da leitura hayekiana da História ou ideia do mercado como passado, presente e devir das sociedades contemporâneas. Contra o pensamento único e um caminho predeterminado a seguir, Arendt nos apresenta a pluralidade e o confronto de opiniões, ação e vida dentro de um verdadeiro espaço que contribui para o interesse público e o engrandecimento libertário da cidade. 


\section{Referências bibliográficas}

ABRANCHES, A. Introdução à

Arendt, H.: a dignidade da política. Rio de Janeiro: Relume

Dumará, 2002

ADLER, L. Nos passos de Hannah Arendt. Cidade: Record, 2007.

ARENDT, H. La crise de la culture. Cidade: Folio-Essais, 1972a.

ARENDT, H. Le systeme totalitaire. France: Loisirs/Editions du Seuil, 1972b.

ARENDT, H. Crises da República. São Paulo: Perspectiva, 1973.

ARENDT, H. Juger: sur la philosophie politique de Kant. France: Editons du Seuil, 1982.

ARENDT, H. A condičão humana. Rio de Janeiro: Forense Universitária, 1987.

ARENDT, H. A dignidade da politica. Cidade: Relume Dumará, 2002.

CORREA, A. Transpondo o abismo: Hannah Arendt entre a Filosofia e a Política. Rio de Janeiro: Forense Universitária, 2002.

COSTA, J. F. O vestígio e a aura: corpo e consumismo na moral do espetáculo. Rio de Janeiro: Garamond, 2004.

DUFOUR, D. R. A arte de reduzir as cabeças: sobre a nova servidão na sociedade liberal. Rio de Janeiro: Companhia de Freud, 2005.
DUPUY, J. P. Introduction aux Sciences Sociales: logique des phénomènes collectives, Paris: Ellipses, 1992.

FERRY, L. Philosophie Politique. Paris: PUF, v. 2, 1984.

GANEM, A. Demonstrar a ordem racional do mercado: reflexões em torno de um projeto impossível. Revista de Economia Política, São Paulo, Nobel Editora, v. 16, n. 2, p. 105-122, abr./jun. 1996.

GANEM, A. Regras e ordem do mercado em Smith e Hayek. Madrid: Endoxa: Series Filosóficas, n. 21, p. 295-312, 2006.

HAYEK, F. A. Individualism and economic order. Chicago: University of Chicago Press, 1937.

HAYEK, F. The counter-revolution of science. Glencoe: Free Press, 1952.

HAYEK, F. Studies in Philosophy, Politics and Economics. Chicago: University of Chicago Press, 1967.

HAYEK, F. Law, legislation and liberty (tomos I, II e III). Cidade: Routledge and Kegan Paul, 1973.

HAYEK, F. Os fundamentos da liberdade. Brasília: Editora Universidade de Brasília, 1983.

HAYEK, F. The fatal conceit: the errors of the socialism. Cidade: Bartley, Routledge, 1988.
HAYEK, F. Essais de Philosophie, de Science Politique et d'Économie. Paris: Lês Belles Lettres, 2007.

LIPOVESTSKY, G. O império do efêmero. São Paulo: Companhia das Letras, 2004.

Este artigo foi apresentado em versões anteriores no XI

- Encontro Anual da

- Sociedade Brasileira de

Economia Política e no II

- Congresso da Associação

- Latino-Americana de

- Ciência Política, ambos em

- 2006. Agradeço os comentários

- dos debatedores desses encontros

- e, especialmente, aos pareceristas

- de Nova Economia. Os errose

- as omissões são meus.

E-mail de contato da autora:

.aganem@terra.com.br

Artigo recebido em julho de 200

aprovado em maio de 2009 . 